\title{
Erratum to: Remote ischemic preconditioning in hemodialysis: a pilot study
}

\author{
Jongha Park • Soe Hee Ann · Hyun Chul Chung • \\ Jong Soo Lee $\cdot$ Shin-Jae Kim $\cdot$ Scot Garg $\cdot$ \\ Eun-Seok Shin
}

Published online: 21 January 2014

(C) Springer Japan 2014

\section{Erratum to: Heart Vessels}

DOI 10.1007/s00380-013-0329-y

Unfortunately, the below information about research fund was not included in the original publication of the article.

This work was funded by Ulsan University Hospital (Biomedical Research Center Promotion Fund 10-02).

The online version of the original article can be found under doi:10.1007/s00380-013-0329-y.

J. Park · H. C. Chung $\cdot$ J. S. Lee

Division of Nephrology, Ulsan University Hospital,

University of Ulsan College of Medicine, 290-3 Jeonha-dong,

Dong-gu, Ulsan 682-714, South Korea

S. H. Ann · S.-J. Kim · E.-S. Shin $(\bowtie)$

Division of Cardiology, Ulsan University Hospital,

University of Ulsan College of Medicine, 290-3 Jeonha-dong,

Dong-gu, Ulsan 682-714, South Korea

e-mail: sesim98@yahoo.co.kr

S. Garg

Division of Cardiology, Royal Blackburn Hospital,

Blackburn, UK 